\title{
Association of serum bilirubin, selected iron status indicators and body composition in non-obese, normoglycemic subjects
}

\author{
Corresponding author: \\ Katarzyna Bergmann, PhD \\ Department of Laboratory Medicine \\ Nicolaus Copernicus University, \\ Collegium Medicum in Bydgoszcz \\ Skłodowskiej-Curie 9 , \\ 85-799 Bydgoszcz, Poland \\ Tel. +48525854490, \\ fax +48525853603 \\ E-mail: bergmann@vp.pl
}

Medical Research Journal 2018; Volume 3, Number 3, 181-187 10.5603/MRJ.a2018.0029 Copyright (C) 2018 Via Medica ISSN 2451-2591

\begin{abstract}
Background: Recently cardiometabolic risk reduction has been observed in patients with slightly elevated bilirubin concentration, as well as increased risk in subjects with excessive iron reserves. The aim of this study was to evaluate the relationship between overweight and/or abdominal obesity, serum bilirubin and selected iron status indicators levels in non-obese subjects.

Methods: The study group consisted of 80 healthy, non-obese subjects aged 25-40 years. In all subjects total and direct bilirubin (T-BIL, D-BIL), iron (Fe), transferrin (TRSF), ferritin (FERR) and hepcidin (HEPC) measurements were performed. Anthropometric parameters (BMI, waist circumference, WHR) were measured and body composition (\% of body fat, muscles and level of visceral fat) was evaluated using body segment analyzer.

Results: Men showed significantly higher values of waist circumference, WHR, muscle mass, visceral fat level and FERR and HEPC concentrations, compared to women. Lower concentrations of T-BIL, D-BIL and higher concentration of FERR, HEPC occurred in the overweight group. In all subjects and in the overweight group T-BIL, D-BIL showed negative correlations with BMI, waist circumference, fat mass and visceral fat level, while for FERR, HEPC those correlations were positive. Overweight subjects had an approximately 4-fold higher incidence of low T-BIL, D-BIL levels ( $p<0,001)$, as well as nearly 2-fold higher incidence of high transferrin level $(p=0,02)$.

Conclusions: Overweight subjects have lower bilirubin levels and higher levels of factors potentially contributing to increased oxidative stress, for example ferritin and hepcidin. Serum bilirubin, ferritin and hepcidin concentration are related to body composition indicators, particullary fat mass and visceral fat level. Key words: bilirubin, antioxidant, iron metabolism, overweight, obesity
\end{abstract}

Med Res J 2018; 3 (4): 181-187

\section{INTRODUCTION}

The incidence of overweight and obesity has increased threefold in the last twenty years, which is a serious health and socio-economic problem. Obesity is involved in the pathogenesis of numerous diseases such as: type 2 diabetes, metabolic syndrome, hypertension, myocardial infarction, ischemic stroke and cancer. In the course of those diseases, inflammatory processes and increased production of free radicals are of great importance. Research over the past several years indicate the protective effect of bilirubin, as a low-molecular antioxidant, on reducing the risk of cardiovascular disease [1]. In its pathogenesis attention was also paid to the important role of iron oxidation processes, leading to increased synthesis of free radicals.

Bilirubin is a product of oxidative heme metabolism in mammals [2]. In this process heme is obtained mainly from hemoglobin, in smaller quantities from other proteins containing heme, i.e. myoglobin and cytochrome P-450 [3]. During its metabolism, bilirubin is modified by esterification with glucuronic acid. The consequence of this process is the formation of ionic derivatives, mono- and diglucuronides, which are excreted together with the bile. It is one of the most important biochemical parameters used to diagnose liver and bile ducts function [4]. 
Iron is a very important micronutrient for living organisms. It is a cofactor for many proteins of various biological significance. It plays a key role in the formation of hemoglobin, myoglobin and many important biochemical pathways, including energy metabolism, the production of neurotransmitters and the function of the immune system. As the transition metal, iron has useful binding properties to redox ligands [5]. Physiologically, the total iron content in the body of an adult male is about $4 \mathrm{~g}$, in women about $3.5 \mathrm{~g}$. The metabolically active iron constitutes $80 \%$ of the total pot, and in this $70 \%$ is contained in hemoglobin. Iron stored in ferritin accounts for approx. $20 \%$ Only a small percentage of iron is associated with transferrin (transport protein) [6].

Studies show that low bilirubin concentration in vivo eliminates free oxygen radicals and thus leads to alleviation of oxidative stress. The unconjugated bilirubin has the property to „sweep” singlet oxygen. In the presence of hydrogen peroxide or organic hydroxides, bilirubin behaves like a reducing agent for some peroxidases, thus minimizing the amount of potential oxidants [7]. In vitro studies have shown that bilirubin combined with albumin removes superoxide radicals from lysosomal systems and homogeneous solutions [8]. The reduction of inflammatory response in the vascular wall, resulting from the elimination of oxidative stress and the inhibition of endothelial cell activation, is associated with both bilirubin and its derivative, biliverdin [7]. Overexpression of heme oxygenase-1 (HO-1), an enzyme that catalyzes the breakdown of heme, reduces the production of inflammatory mediators, as well as indirectly affects vasodilation, stimulating the expression and production of nitric oxide [9]. Using its antioxidant activity, bilirubin can reduce lipid oxidation by eliminating free radicals and inactivating oxidized lipoproteins (especially LDL) and lipids, resulting in the inhibition of atherosclerotic plaque production [10]. In addition, the plasma concentration of bilirubin correlates inversely with many risk factors for coronary heart disease, including smoking, increased LDL-cholesterol, diabetes, and obesity, while it is positively correlated with HDL cholesterol, which has cardioprotective properties [11].

Excess iron level is considered to be harmful, because it promotes the formation of free radicals, which leads to tissue damage or oxidative stress [12]. Free radicals cause damage to molecules such as proteins, lipids and DNA. Such damaged biomolecules may be involved in the pathogenesis of numerous diseases, for example through co-participation in the process of atherosclerotic plaque formation. [13]. Epidemiological studies have also shown that high levels of iron in the body are associated with increased risk of coronary artery disease [12]. The largest source of iron is the breakdown of heme. During normal metabolism, iron is bound by ferritin to protect cells. In plasma, it is bound and transported by transferrin [7].
Iron as a free active metal occurs in very small amounts. Free iron along with hydrogen peroxide and superoxide anion radical in the Haber-Weiss reaction produce a very toxic hydroxyl radical $(\mathrm{OH})$. The $\mathrm{OH}$ radical may be the initiator of lipid peroxidation, by separating the hydrogen atom from the polyunsaturated fatty acid molecule. The lipid peroxides formed in this process with the participation of iron may initiate additional lipid peroxidation [13]. OH also leads to LDL peroxidation, low density lipoprotein molecules. This process leads to the formation of oxidized LDL (ox-LDL) with strong atherogenic properties [6].

Several studies suggest that in overweight/obese subjects iron deficiency is more common, as well as higher ferritin levels. Therefore it seems that the pro-oxidative effects of iron and its relationship to adipose tissue depend not on its serum concentration, but primarily on the iron storage pool [14].

According to recent studies, inflammatory activity of adipose tissue may be strongly associated with disturbances of endogenous antioxidants and potential oxidants, including bilirubin and iron, which is why their determination may be important in assessing the risk of cardiometabolic disorders. The aim of the study was to evaluate the relationship between overweight and/or abdominal obesity, serum bilirubin and selected iron status indicators (iron, transferrin, ferritin, hepcidin) concentration in non-obese, non-smoking subjects with normal fasting glycaemia.

\section{Subjects, materials and methods}

Study consisted of 80 non-obese (BMI 18.5$27.0 \mathrm{~kg} / \mathrm{m}^{2}$ ), non-smoking and normoglycemic (fasting glucose $60-99 \mathrm{mg} / \mathrm{dL}$ ) subjects aged $25-40$ years (40 women, 40 men). Basic anthropometric measurements (body weight, waist circumference, BMI, WHR), blood pressure measurements with an automatic blood pressure monitor Omron M6 Comfort (Omron Healthcare, Kyoto, Japan) and medical history of chronic diseases were performed.

Serum and fluoride plasma were collected in the morning (7.00-9.00 am) after 12 hours of fasting. Samples were centrifuged in low temperature $\left(4^{\circ} \mathrm{C}\right)$. Laboratory tests: plasma glucose and total and direct bilirubin (T-BIL, D-BIL), iron (Fe), transferrin (TRSF) and ferritin (FERR) in serum were performed on $A B X$ Pentra 400 autoanalyzer (Horiba Ltd., Kyoto, Japan). Serum samples were divided into small aliquots and were frozen in $-70^{\circ} \mathrm{C}$ to avoid peptides degradation for further assays. Concentration of serum hepcidin (HEPC) was determined using Hepcidin 25 (Bioactive) HS enzyme-linked immunosorbent assay (ELISA) kit (DRG Diagnostics GmbH, Marburg, Germany). The limit of detection was $0.30 \mathrm{ng} / \mathrm{mL}$. 
All laboratory measurements were performed in the Department of Laboratory Medicine, Nicolaus Copernicus University Collegium Medicum in Bydgoszcz, Poland.

Body composition (percentage of body fat, muscles and level of visceral fat) was evaluated using body segment analyzer based on electrical bioimpedance (BIA) technology (InnerScan V BC-545N, Tanita). Measurements were performed fasting, in the morning, directly before blood samples collection and in accordance with the manufacturer's instructions. The reference values of these parameters depend on age and for 25-40 year olds the following values were adopted: fat mass women $21-33 \%$, men 8-20\%; level of visceral fat: 1-12; muscle mass women $>24 \%$, men $>33 \%$ (according to manufacturer's manual).

Statistical analysis was performed using STATISTICA 12.0 PL software (StatSoft Inc. 2014). Data were presented as mean \pm standard deviation (normal distribution) or median and $25^{\text {th }}-75^{\text {th }}$ percentile (non-Gaussian distribution). Differences between study groups were calculated by t-Student, U-Mann-Whitney and ANOVA Kruskal-Wallis tests. $P$ value $<0.05$ was considered statistically significant.

The study was approved by the Bioethics Committee at the Nicolaus Copernicus Univeristy Collegium Medicum in Bydgoszcz, Poland (No. KB 627/2010) and complied with the World Medical Association Declaration of Helsinki regarding ethical conduct of research involving human subjects. From all participants involved in this study an informed written consent was obtained.

\section{Results}

In the study group, total bilirubin concentrations ranged 10.9-17.8 $\mu \mathrm{mol} / \mathrm{L}$. Higher, but statistically insignificant, medians of total and direct bilirubin and iron were observed in men, compared to women (Table 1). In women statistically significantly lower values of the following parameters were found: waist circumference, WHR, muscle mass, level of visceral tissue, ferritin and hepcidin. Table 2 shows the comparison of the measured parameters in subjects with normal body weight and overweight. Statistically significant higher concentrations of total and direct bilirubin were observed in normal weight subjects. In contrast, overweight subjects have significantly higher concentrations of ferritin and hepcidin.

In the analysis of the relationship between body composition and biochemical parameters (Table 3 ), positive correlations between ferritin and hepcidin with waist circumference, WHR, fat mass and level of visceral fat were observed. However, a negative correlation was found between total and direct bilirubin with BMI, waist circumference, fat mass and level of visceral fat. In addition, total bilirubin and hepcidin showed significant relationships with muscle mass. Iron correlated weakly only with fat mass. The correlation was analyzed also in the group of subjects with normal weight and overweight. In subjects with normal body weight, only negative correlations of total and direct bilirubin with BMI $(R=-0.48$ and $-0.40 ; p<0,001$, respectively) and waist circumference were observed $(R=-0.32$ and -0.35 ; $p<0.05$, respectively) and positive weak correlation of ferritin and hepcidin with waist circumference

Table 1. Clinical and biochemical characteristics of study group

\begin{tabular}{|c|c|c|c|c|}
\hline Variables & Study group $(n=80)$ & Women $(n=40)$ & Men $(n=40)$ & $\mathbf{p}$ \\
\hline Age (years) & $31(27-35)$ & $32(26-37)$ & $30(27-33)$ & ns \\
\hline BMI $\left[\mathrm{kg} / \mathrm{m}^{2]}\right.$ & $24.3( \pm 3.04)$ & $24,33( \pm 3.53)$ & $24,28( \pm 2,51)$ & ns \\
\hline Waist [cm] & 87 (76-91.5) & $78.5(70-89)$ & $88,5(84-93)$ & 0,001 \\
\hline WHR & $0,83( \pm 0.07)$ & $0,78( \pm 0,06)$ & $0,87( \pm 0,05)$ & $<0,001$ \\
\hline Fat mass [\%] & $24.4 \pm 6.6$ & $28.2 \pm 5.4$ & $20.6 \pm 5.4$ & $<0,001$ \\
\hline Muscle mass [\%] & $46 \pm 12.5$ & $40 \pm 3.3$ & $51.9 \pm 7.7$ & $<0,001$ \\
\hline Visceral fat level & $4.0(2.3-6.0)$ & $2.8(1.5-4.0)$ & $5,75(4,0-8,0)$ & $<0,001$ \\
\hline $\mathrm{T}-\mathrm{BIL}[\mu \mathrm{mol} / \mathrm{L}]$ & $13.2(10.9-17.8)$ & $12,3(8,7-17,9)$ & $15,4(12,3-17,8)$ & ns \\
\hline D-BIL $(\mu \mathrm{mol} / \mathrm{L})$ & $2.7(2.2-3.6)$ & $2.6(2.1-3.4)$ & $3.1(2.4-3.6)$ & ns \\
\hline $\mathrm{Fe}(\mu \mathrm{mol} / \mathrm{L})$ & $17.8( \pm 5.9)$ & $16.8( \pm 5.7)$ & $18.8( \pm 6.1)$ & ns \\
\hline $\operatorname{TRSF}(\mu \mathrm{mol} / \mathrm{L})$ & $32.2(29.1-36.2)$ & $33.3(28.3-39.3)$ & $30.5(29.3-33.9)$ & ns \\
\hline FERR (nmol/L) & $1,31(0.64-2.31)$ & $0,70(0,44-1,21)$ & $1,84(1.35-2.65)$ & $<0,001$ \\
\hline HEPC (ng/mL) & $19.4(8.4-33.2)$ & $12.9(4.9-24.0)$ & $27,6(16.6-35.4)$ & 0,002 \\
\hline
\end{tabular}

Data presented as mean \pm SD or median (25-75\%)

$n s-$ statistically insignificant $(p>0,05)$ 
Table 2. Comparison of variables in normal weight and overweight subjects

\begin{tabular}{|c|c|c|c|}
\hline Variables & $\begin{array}{l}\text { Normal body weight } \\
\text { BMI } 18.5-24.9 \mathrm{~kg} / \mathrm{m}^{2} \\
(\mathrm{n}=44)\end{array}$ & $\begin{array}{c}\text { Overweight } \\
\text { BMI } 25.0-27.0 \mathrm{~kg} / \mathrm{m}^{2} \\
(\mathrm{n}=36)\end{array}$ & $\mathrm{p}$ \\
\hline Age (years) & $28(26-32)$ & 33 (27-37) & 0,048 \\
\hline BMI $\left[\mathrm{kg} / \mathrm{m}^{2]}\right.$ & $21,88( \pm 1,86)$ & $26,73 \pm 1,76$ & $<0,001$ \\
\hline Waist [cm] & 77.5 (68-84) & 91 (87-94) & $<0,001$ \\
\hline WHR & $0.8 \pm 0.07$ & $0,85( \pm 0,06)$ & 0,002 \\
\hline Fat mass [\%] & $20.5(16.2-26.5)$ & $24.4(21.1-29.0)$ & 0,03 \\
\hline Muscle mass [\%] & $49.0(39.2-57.6)$ & $40,2(32.2-51.5)$ & 0,02 \\
\hline Visceral fat level & $3.0(2.0-5.0)$ & $7.5(2.5-11.0)$ & $<0,001$ \\
\hline T-BIL $[\mu \mathrm{mol} / \mathrm{L}]$ & $16.6(12.5-19.5)$ & $12.1(8.4-14.4)$ & $<0,001$ \\
\hline D-BIL $[\mu \mathrm{mol} / \mathrm{L}]$ & $3.2(2.7-3.9)$ & $2.4(1.8-3.1)$ & $<0,001$ \\
\hline $\mathrm{Fe}[\mu \mathrm{mol} / \mathrm{L}]$ & $19.1 \pm 6.3$ & $16.6( \pm 5.3)$ & ns \\
\hline TRSF $(\mu \mathrm{mol} / \mathrm{L})$ & $31.4(28.3-33.5)$ & $33.4(29.8-37.4)$ & ns \\
\hline FERR (nmol/L) & $1,14(0,59-2,18)$ & $1,33(1.15-2.33)$ & 0,03 \\
\hline HEPC (ng/mL) & $14.3(7.2-25.1)$ & $23.2(13.8-32.2)$ & 0,02 \\
\hline
\end{tabular}

ns - not significant differences $(p>0,05)$

Table 3. Selected correlation coefficient values in study group ( $\log _{10}-$ transformed variables)

\begin{tabular}{|c|c|c|c|c|c|c|}
\hline Variables & T-BIL & D-BIL & $\mathrm{Fe}$ & TRSF & FERR & HEPC \\
\hline BMI & $-0,48^{* *}$ & $-0,4^{*}$ & ns & ns & ns & ns \\
\hline Waist & $-0,32^{\star}$ & $-0,35^{\star}$ & ns & ns & $0,29 *$ & $0,37^{* *}$ \\
\hline WHR & ns & ns & ns & ns & $0,32^{*}$ & $0,33^{*}$ \\
\hline Fat mass [\%] & $-0,36^{*}$ & $-0,31^{*}$ & $-0,26^{*}$ & ns & $0,32^{*}$ & $0,44^{\star *}$ \\
\hline Muscle mass [\%] & 0,31 * & ns & ns & ns & ns & $-0,30 *$ \\
\hline Visceral fat level & $-0,42^{\star *}$ & $-0,29 *$ & ns & $-0,28^{*}$ & 0,31 & $0,38^{* *}$ \\
\hline
\end{tabular}

${ }^{*} p<0,05 ;{ }^{* *} p<0,001$

Table 4. Correlation between body composition and selected biochemicals parameters in overweight subjects

\begin{tabular}{|c|c|c|c|c|}
\hline Variables & T-BIL & D-BIL & FERR & HEPC \\
\hline BMI & $-0,48^{* *}$ & $-0,40$ ** & ns & ns \\
\hline Waist & $-0,32^{\star}$ & $-0,35^{\star}$ & $0,29 *$ & $0,37^{*}$ \\
\hline WHR & ns & ns & $0,32^{*}$ & $0,33^{*}$ \\
\hline Fat mass [\%] & $-0,45^{\star \star}$ & $-0,42^{\star *}$ & $0,35^{*}$ & $0,46^{* *}$ \\
\hline Muscle mass [\%] & $0,42^{* *}$ & ns & ns & $-0,42^{* *}$ \\
\hline Visceral fat level & $-0,38^{*}$ & $-0,26^{*}$ & $0,36^{*}$ & $0,40^{\star *}$ \\
\hline
\end{tabular}

${ }^{*} \mathrm{p}<0,05 ;{ }^{* *} \mathrm{p}<0,001$

(data not presented). In the overweight group (Table 4) both total and direct bilirubin were correlated with $\mathrm{BMI}$, waist circumference, fat mass and level of visceral fat. However, ferritin and hepcidin showed opposite relationships with body composition. In addition, a significant relationship was found between total bilirubin and hepcidin with muscle mass $(R=0.42$ and -0.41 ; $p<0,001$, respectively).

The frequency of selected biochemical changes in individuals with normal weight and overweight was compared. Low values, corresponding to first tertile, were used for total and direct bilirubin and iron. A higher 


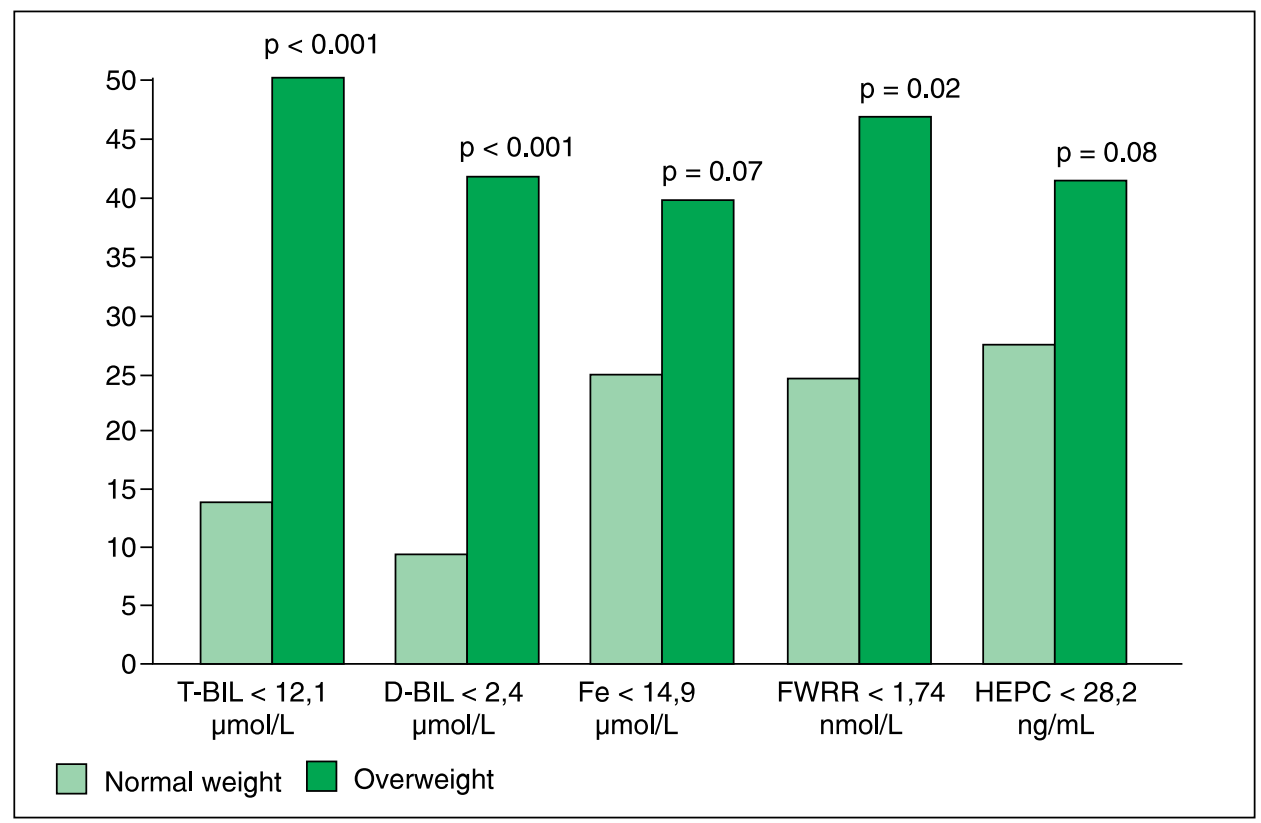

Figure 1. Prevalence of low T-BIL, D-BIL, Fe and high FERR and HEPC levels in normal weight and overweight subjects

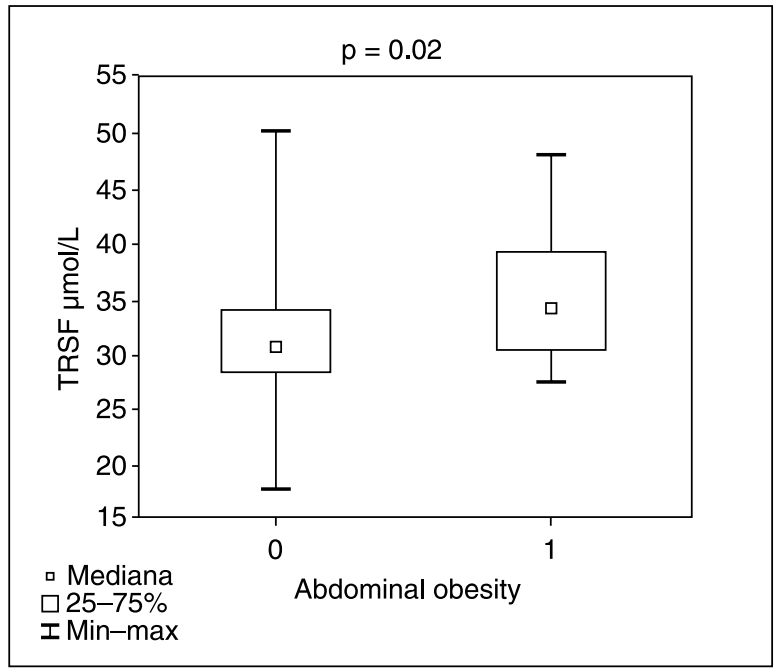

Figure 2. Difference in transferrin levels in subject with (1) and without (0) abdominal obesity

percentage of subjects with low total $(<12,1 \mu \mathrm{mol} / \mathrm{L})$ and direct $(<2.4 \mu \mathrm{mol} / \mathrm{L})$ bilirubin was observed in the overweight group, as well as tendency for low levels of iron $(<14.9 \mu \mathrm{mol} / \mathrm{L})$. Hepcidin and ferritin concentration values corresponding to their third tertile (> $28.18 \mathrm{ng} / \mathrm{mL}$; $>1.74 \mathrm{nmol} / \mathrm{L}$ ) were found more often in overweight subjects ( $41.6 \%$ and $47.2 \%$, respectively), compared to normal weight group. In addition, statistically significant higher concentration of transferrin (Figure 2) was observed in patients with abdominal obesity, defined by waist circumference $(\geq 80 \mathrm{~cm}$ in women and $\geq 94 \mathrm{~cm}$ in men).

\section{Discussion}

Bilirubin, the final product of heme metabolism, for many years was considered a toxic, side product. However, studies from the last years suggest that bilirubin is a strong endogenous antioxidant [15]. It belongs to the low molecular weight antioxidants, which low concentrations protect against oxidation or delays this process. This group also includes compounds such as: glutathione, uric acid, carnitine, flavonoids and vitamins $A, C$ and $E$.

Obesity, especially of the abdominal type, is associated with low-grade inflammation in adipocytes. Inflammation leads to the development of insulin resistance and type 2 diabetes. Adipocytes in obese subjects produce large amounts of proinflammatory cytokines: TNF- $\alpha$ (tumor necrosis factor $\alpha$ ) and interleukin 6, whose concentration is under physiological conditions decreased by $\mathrm{HO}-1$, involved in the synthesis of bilirubin. It can be assumed that in obese subjects, the concentration of bilirubin in the blood may be lower than in people with normal body weight [16]. Oxidative stress initiated by the iron oxidation activity is involved in the pathogenesis of many diseases, i.e. diabetes or atherosclerosis [13]. A common risk factor in these diseases is also overweight or obesity, which also affect iron metabolism. In obese subjects hepcidin concentration, produced by adipocytes, is significantly increased. It inhibits the intestinal absorption of iron and its release from macrophages and liver, leading to its accumulation in the body [17]. Therefore, it is suggested that overweight or obese individuals may have higher values of iron status indicators, which may reflect an increased risk of cardiometabolic disorders. 
In this study, overweight subjects had statistically significantly lower total and direct bilirubin concentrations. Andersson et al. stated that the lower body fat content and weight loss are associated with increased bilirubin [18]. Similarly, Swift et al. observed that aerobic physical training has a beneficial effect on body weight, and thus may increase the concentration of bilirubin [19]. In the last years, attention has been paid to the relationship between Gilbert's syndrome and the risk of ischemic heart disease. Maruhasi et al. in their study showed that patients with Gilbert's syndrome have low oxidative stress, resulting from genetically conditioned hyperbilirubinemia, which protects endothelium. This beneficial effect on blood vessels may contribute to the reduction of vascular complications in atherosclerosis in patients with Gilbert's syndrome, compared to patients without the syndrome [20]. There is increasing evidence that moderately elevated concentrations of iron stores, below the values found in genetic hemochromatosis, may adversely affect the cardiovascular system as well as lipid and carbohydrate metabolism. In population studies, elevated levels of ferritin have been shown to be associated with hypertension, dyslipidemia, elevated insulin and glucose, and abdominal obesity. In several studies, the relation between elevated iron concentration and the occurrence of metabolic syndrome was also observed [21].

Serum ferritin concentration is a good indicator of iron stores in the body. Epidemiological studies have shown that increased ferritin levels are associated with an increased cardiometabolic risk [22]. In this study, significant differences in the concentration of ferritin were observed, depending on the sex and BMI values. De Goda et al. reported a relationship between high ferritin concentration and the degree of coronary stenosis in women with obstructive coronary artery disease. In the case of men, its concentration was not a prognostic element of the degree of vessel obstruction [23]. Escobar-Morreale et al. also observed higher concentration of ferritin in the group of women with polycystic ovary syndrome and overweight than in women with normal body weight [24]. The relationship between ferritin concentration and obesity was also noted in the study by Williams et al. The study group consisted of 815 young men and women under 26 years of age. In women, ferritin correlated with waist circumference, BMI, triglycerides and C-reactive protein (CRP) concentration [25]. It is worth noting that ferritin may be treated as an indicator of inflammation, which is increased in abdominal obesity and results from the pro-inflammatory activity of visceral adipose tissue.

Several studies suggest a connection between iron deficiency and overweight/obesity. In a study conducted by Nead et al. on the overweight children and adolescents group, iron deficiency was observed frequently in this group. The incidence of iron deficiency increased with the increase in BMI values [26]. The higher incidence of iron deficiency in overweight children and adolescents compared to the normal body group was also found in the study by Pinhas-Hamiel et al. In the study, higher iron concentrations were also observed in the normal body group [27]. The association of iron deficiency with obesity is explained in several ways. Due to the overexpression of hepcidin in obese people, intestinal iron absorption is inhibited. Moreover, on account of low-grade inflammation, the iron does not fulfill its physiological role [28].

Hepcidin is recently consider as one of the most important regulators of iron metabolism. Cheng et al. showed in their study the relationship between obesity and minor disturbances of iron metabolism. In the group of healthy young women with overweight and obesity, the median concentration of hepcidin was $6.4 \mathrm{ng} / \mathrm{mL}$. The lowest concentrations of hepcidin were observed in subjects with lower iron concentrations [29]. However, in a population study conducted on a group of 1391 individuals, Martinelli et al. noted an elevated concentration of hepcidin in patients with metabolic syndrome. For both women and men, the hepcidin concentration increased with increasing concentration of classic risk factors, as well as of ferritin. In addition, it was concluded that in the metabolic syndrome, the hepcidin concentration gradually increases in response to a moderate increase in iron stores in the body [30].

The results of own research in the group of healthy, young people allow to determine the relationship between the weight, body composition and the concentration of both total and direct bilirubin, as well as selected iron status indicators, particularly the concentration of ferritin and hepcidin. The interaction between oxidative stress, inflammation and iron metabolism has not been fully understood, which makes it difficult to determine the exact role of iron as a cardiometabolic risk factor. The results obtained in this study may suggest an important role of the analyzed parameters in the diagnosis of cardiometabolic disorders. However, despite the promising results in this study, attention should be paid to its limitations, especially a small number of respondents. Therefore, the results would require verification in a large population-based study.

Disclosure of interest: The authors state that there are no conflicts of interestregarding the publication of this article.

\section{List of abbreviations}
$\mathrm{BIA}$ - bioelectrical impedance analysis
$\mathrm{BMI}$ - body mass index
CRP - C-reactive protein 


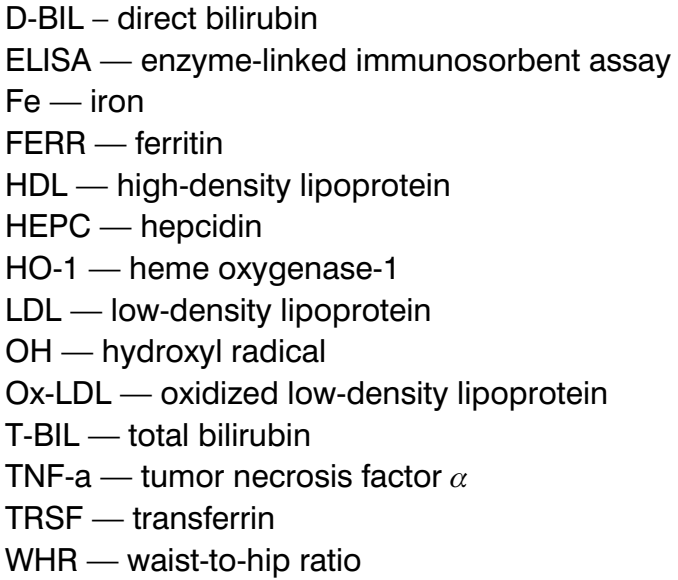

\section{References}

1. Troughton J, Woodside J, Young I, et al. Bilirubin and coronary heart disease risk in the Prospective Epidemiological Study of Myocardial Infarction (PRIME). European Journal of Cardiovascular Prevention \& Rehabilitation. 2016; 14(1): 79-84, doi: 10.1097/01. hjr.0000230097.81202.9f.

2. Wiwanitkit $\mathrm{V}$. Energy change in the formation of conjugated bilirubin: a possible responsive mechanism for liver cell pathology. Rev Esp Enferm Dig. 2007; 99(2): 94-95, indexed in Pubmed: 17417921

3. Leszczyńska-Gołąbek I, Kuśnierz-Cabala B. Diagnostyka laboratoryjna chorób przewodu pokarmowego watroby i trzustki. In: Dembińska-Kieć A, Naskalski JW ed. Diagnostyka laboratoryjna z elementami biochemii klinicznej. Elsevier Urban \& Partner, Wrocław. ; 2015: 753-759.

4. Bergmann K, Pachota E, Odrowąż-Sypniewska G. Association of serum total bilirubin with traditional and novel cardiovascular risk factors in apparently healthy subjects. Folia Med Coper. 2015; 3(1): 26-31.

5. Edison ES, Bajel A, Chandy M. Iron homeostasis: new players, newer insights. Eur J Haematol. 2008; 81(6): 411-424, doi: 10.1111/j.1600-0609.2008.01143.x, indexed in Pubmed: 18754855.

6. Podolecki T, Wasilewski J, Poloński L. Potencjalna rola żelaza w etiopatogenezie choroby wieńcowej. Chor Serca i Naczyń. 2009; 6(4): 180-183.

7. Abraham NG, Kappas A. Pharmacological and Clinical Aspects of Heme Oxygenase. Pharmacological Reviews. 2008; 60(1): 79-127, doi: 10.1124/pr.107.07104.

8. Maghzal GJ, Leck MC, Collinson E, et al. Limited role for the bilirubin-biliverdin redox amplification cycle in the cellular antioxidant protection by biliverdin reductase. J Biol Chem. 2009; 284(43): 29251-29259, doi: 10.1074/jbc.M109.037119, indexed in Pubmed: 19690164.

9. Kawamura K, Ishikawa K, Wada Y, et al. Bilirubin from heme oxygenase-1 attenuates vascular endothelial activation and dysfunction. Arterioscler Thromb Vasc Biol. 2005; 25(1): 155-160, doi: 10.1161/01. ATV.0000148405.18071.6a, indexed in Pubmed: 15499042.

10. McArdle PF, Whitcomb BW, Tanner K, et al. Association between bilirubin and cardiovascular disease risk factors: using Mendelian randomization to assess causal inference. BMC Cardiovasc Disord. 2012; 12: 16 , doi: $10.1186 / 1471-2261-12-16$, indexed in Pubmed: 22416852

11. Endler G, Hamwi A, Sunder-Plassmann R, et al. Is low serum bilirubin an independent risk factor for coronary artery disease in men but not in women? Clin Chem. 2003; 49(7): 1201-1204, indexed in Pubmed: 12816925.
12. Choi JW, Kim SK, Pai SH. Changes in serum lipid concentrations during iron depletion and after iron supplementation. Ann Clin Lab Sci. 2001; 31(2): 151-156, indexed in Pubmed: 11337904.

13. Oliński R, Jurgowiak M. Zelazo, wolne rodniki i oksydacyjne uszkodzenia DNA a choroba miażdżycowa. Acta Angiol. 2002; 8(2): 37-44.

14. Zeid AA, Saka MEI, Abdalfattah A, et al. Potential factors contributing to poor iron status with obesity. Alexandria Journal of Medicine. 2014 50(1): 45-48, doi: 10.1016/j.ajme.2013.04.007.

15. Mayer M. Association of serum bilirubin concentration with risk of coronary artery disease. Clin Chem. 2000; 46(11): 1723-1727, indexed in Pubmed: 11067805

16. Hosick PA, Stec DE. Heme oxygenase, a novel target for the treatment of hypertension and obesity? Am J Physiol Regul Integr Comp Physiol. 2012; 302(2): R207-R214, doi: 10.1152/ajpregu.00517.2011, indexed in Pubmed: 22071158

17. Przybyszewska J, Żekanowska E, Kędziora-Kornatowska K, et al. Comparison of serum prohepcidin and iron metabolism parameters in obese and non-obese elderly individuals. Endokrynol Pol. 2013; 64(4): 272-277, indexed in Pubmed: 24002954.

18. Andersson C, Weeke P, Fosbøl EL, et al. SCOUT Executive Steering Committee, SCOUT investigators. Acute effect of weight loss on levels of total bilirubin in obese, cardiovascular high-risk patients: an analysis from the lead-in period of the Sibutramine Cardiovascular Outcome trial. Metabolism. 2009; 58(8): 1109-1115, doi: 10.1016/j. metabol.2009.04.003, indexed in Pubmed: 19454355.

19. Swift DL, Johannsen NM, Earnest CP, et al. Effect of different doses of aerobic exercise training on total bilirubin levels. Med Sci Sports Exerc. 2012; 44(4): 569-574, doi: 10.1249/MSS.0b013e3182357dd4, indexed in Pubmed: 21900842

20. Maruhashi T, Soga J, Fujimura N, et al. Hyperbilirubinemia, augmentation of endothelial function, and decrease in oxidative stress in Gilbert syndrome. Circulation. 2012; 126(5): 598-603, doi: 10.1161/CIRCULATIONAHA.112.105775, indexed in Pubmed: 22773454.

21. Jehn M, Clark JM, Guallar E. Serum ferritin and risk of the metabolic syndrome in U.S. adults. Diabetes Care. 2004; 27(10): 2422-2428, indexed in Pubmed: 15451911.

22. You SA, Wang Q. Ferritin in atherosclerosis. Clinica Chimica Acta 2005; 357(1): 1-16, doi: 10.1016/j.cccn.2005.02.001.

23. de Godoy MF, Takakura IT, Machado RD, et al. Serum ferritin and obstructive coronary artery disease: angiographic correlation. Arq Bras Cardiol. 2007; 88(4): 430-433, indexed in Pubmed: 17546273.

24. Escobar-Morreale HF, Luque-Ramirez M, Alvarez-Blasco F, et al. Body Iron Stores Are Increased in Overweight and Obese Women With Polycystic Ovary Syndrome. Diabetes Care. 2005; 28(8): 2042-2044, doi: 10.2337/diacare.28.8.2042

25. Williams MJA, Poulton R, Williams S. Relationship of serum ferritin with cardiovascular risk factors and inflammation in young men and women. Atherosclerosis. 2002: 165(1): 179-184 indexed in Pubmed: 12208485

26. Nead KG, Halterman JS, Kaczorowski JM, et al. Overweight children and adolescents: a risk group for iron deficiency. Pediatrics. 2004; 114(1): 104-108, indexed in Pubmed: 15231915.

27. Pinhas-Hamiel O, Newfield RS, Koren I, et al. Greater prevalence of iron deficiency in overweight and obese children and adolescents. Int J Obes Relat Metab Disord. 2003; 27(3): 416-418, doi: 10.1038/sj.ijo.0802224, indexed in Pubmed: 12629572.

28. Zafon C, Lecube A, Simó R. Iron in obesity. An ancient micronutrient for a modern disease. Obes Rev. 2010; 11(4): 322-328, doi: 10.1111/j.1467-789X.2009.00638.x, indexed in Pubmed: 19619262

29. Cheng HL, Bryant CE, Rooney KB, et al. Iron, hepcidin and inflammatory status of young healthy overweight and obese women in Australia. PLoS One. 2013; 8(7): e68675, doi: 10.1371/journal.pone.0068675, indexed in Pubmed: 23861932

30. Martinelli N, Traglia M, Campostrini N, et al. Increased serum hepcidin levels in subjects with the metabolic syndrome: a population study. PLoS One. 2012; 7(10): e48250, doi: 10.1371/journal.pone.0048250, indexed in Pubmed: 23144745. 